\title{
Changes in Sagittal Alignment Following Short-Level Lumbar Interbody Fusion: Comparison between Posterior and Lateral Lumbar Interbody Fusions
}

\author{
Hiroaki Nakashima ${ }^{1}$, Tokumi Kanemura ${ }^{1}$, Kotaro Satake ${ }^{1}$, Yoshimoto Ishikawa ${ }^{1}$, \\ Jun Ouchida ${ }^{1}$, Naoki Segi ${ }^{2}$, Hidetoshi Yamaguchi ${ }^{2}$, Shiro Imagama ${ }^{2}$ \\ ${ }^{1}$ Department of Orthopedic Surgery, Konan Kosei Hospital, Konan, Japan \\ ${ }^{2}$ Department of Orthopedic Surgery, Nagoya University Graduate School of Medicine, Nagoya, Japan
}

\begin{abstract}
Study Design: Retrospective case-control study.
Purpose: We aimed to compare radiologic outcomes between posterior (PLIF) and lateral lumbar interbody fusion (LLIF) in short-level spinal fusion surgeries.

Overview of Literature: Although LLIF enables surgeons to insert large lordotic cages, it is unknown whether LLIF more effectively corrects local and global sagittal alignments compared with PLIF in short-level spinal fusion surgeries.

Methods: Radiographic data acquired from patients with lumbar interbody fusion ( $\leq 3$ levels) using PLIF or LLIF for degenerative lumbar diseases were analyzed. The following radiographic parameters were evaluated preoperatively and at 2 years postoperatively: segmental lordotic angle, disk height, lumbar lordosis (LL), pelvic tilt (PT), C7 sagittal vertical axis, and thoracic kyphosis (TK).

Results: In total, 144 patients with PLIF (193 fused levels) and 101 with LLIF (159 fused levels) were included. Patients' backgrounds and preoperative radiographic parameters for any level of fusion did not differ significantly between PLIF and LLIF procedures. The LLIF group exhibited significantly greater changes at 1-level fusion compared to the PLIF group in the parameters of segmental lordotic angle $\left(5.1^{\circ} \pm 5.8^{\circ}\right.$ vs. $\left.2.1^{\circ} \pm 5.0^{\circ}, p<0.001\right)$, disk height $(4.2 \pm 2.3 \mathrm{~mm}$ vs. $2.2 \pm 2.0 \mathrm{~mm}, p<0.001), \mathrm{LL}\left(7.8^{\circ} \pm 7.6^{\circ}\right.$ vs. $\left.3.9^{\circ} \pm 8.6^{\circ}, p=0.004\right)$, and $\mathrm{PI}-\mathrm{LL}\left(-6.9^{\circ} \pm 6.8^{\circ}\right.$ vs. $\left.-3.6^{\circ} \pm 10.1^{\circ}, p=0.03\right)$. While, a similar trend was observed regarding 2-level fusion, significantly greater changes were only observed in $\mathrm{LL}\left(12.1^{\circ} \pm 11.1^{\circ}\right.$ vs. $\left.4.2^{\circ} \pm 9.1^{\circ}, p=0.047\right)$ and $\mathrm{PI}-\mathrm{LL}\left(-11.2^{\circ} \pm 11.3^{\circ}\right.$ vs. $\left.-3.0^{\circ} \pm 9.3^{\circ}, p=0.043\right), \mathrm{PT}\left(-6.4^{\circ} \pm 4.9^{\circ}\right.$ vs. $\left.-2.5^{\circ} \pm 5.3^{\circ}, p=0.049\right)$ and TK $\left(7.8^{\circ} \pm 11.8^{\circ}\right.$ vs. $\left.-0.3^{\circ} \pm 9.7^{\circ}, p=0.047\right)$ in the LLIF group at 3 -level fusion.

Conclusions: LLIF provides significantly better local sagittal alignment than PLIF in 1- or 2-level fusion cases and improves spinopelvic alignment and local alignment for 3-level fusion cases. Thus, LLIF was demonstrated to be a useful lumbar interbody fusion technique, constituting a powerful tool for achieving sagittal realignment with minimal surgical invasiveness.
\end{abstract}

Keywords: Lateral lumbar interbody fusion; Posterior lumbar interbody fusion; Global sagittal alignment; Local sagittal alignment; Disc height; Lumbar lordosis

Received Jan 15, 2019; Revised Mar 4, 2019; Accepted Mar 6, 2019

Corresponding author: Hiroaki Nakashima

Department of Orthopedic Surgery, Konan Kosei Hospital, 137 Takayamachi Omatsubara, Konan 483-8704, Japan

Tel: +81-587-51-3333, Fax: +81-587-51-3300, E-mail: hirospine@gmail.com 


\section{Introduction}

The importance of sagittal alignment has been recognized in degenerative lumbar disease surgery. Restoration of sagittal plane balance is associated closely with favorable patient outcomes in spinal deformity surgeries, including reduced pain, minimal disability, and better quality of life $[1,2]$. Due to the well documented prominence of spinopelvic sagittal balance, lumbar lordosis (LL), correlated with pelvic incidence (PI), is considered a requirement for a balanced sagittal posture [3]. Adequate LL followed by sufficient thoracic kyphosis (TK) could lead to harmonious global sagittal balance, resulting in favorable clinical and radiologic outcomes [4]. Though the importance of sagittal balance restoration in short-level degenerative lumbar fusion surgery was underestimated previously, progress in research on global sagittal balance has thrust sagittal balance restoration into the spotlight. Lack of adequate LL achieved following fusion surgery can accelerate degeneration of adjacent segments $[5,6]$, potentially resulting in a poor quality of life and overall function [2]. Consequently, lumbar hypolordosis following previous posterior fusion surgery has become a growing problem in recent years [7].

Though short-level lumbar interbody fusion surgery is known to improve local sagittal alignment, its effects on regional LL and global sagittal alignment remain unclear [8]. Lateral lumbar interbody fusion (LLIF) is an alternative technique to conventional anterior and posterior lumbar interbody fusion (PLIF) for managing various pathologies of degenerative lumbar diseases $[9,10]$. LLIF is a minimally invasive surgical method that permits the placement of interbody cages that are larger in size than those placed using PLIF [9-11]. This alternative method might provide a better radiologic restoration and sufficient correction of local and regional LL or may somewhat restore global sagittal alignment.

However, there is a paucity of data on postoperative changes in regional LL and global sagittal parameters following short-level PLIF and LLIF. Additionally, the lack of studies that compare the impact of radiographic changes yielded by the two surgical techniques warranted the conduct of the current study to compare the radiographic impact of LLIF and PLIF on local and global sagittal alignments.

\section{Materials and Methods}

\section{Study design}

After obtaining approval from Konan Kosei Hospital ethics comittees (IRB approved no., 25-022[0174]), we prospectively enrolled and retrospectively reviewed the radiographic records of consecutive patients who underwent PLIF between 2009 and 2013, and who underwent LLIF between 2013 and 2016. The following were the exclusion criteria: (1) revision surgery, (2) $\geq 4$-level involvement, (3) L5-S fusion surgery, (4) decompression surgery at another level, (5) $\geq$ grade 2 osteotomy on the Schwab classification [12], (6) a coronal Cobb angle $>20^{\circ}$, (7) $<2$ years of follow-up, (8) additional spine surgery during the follow-up period, and (9) other disease entities, such as tumors, traumas, or infections. Finally, 245 patients were included in this study: 144 consecutive patients who had undergone PLIF (average age, 67.19 \pm 11.90 years; male, 68; female, 76) and 101 consecutive patients who had undergone LLIF (average age, 70.95 \pm 6.24 years; male, 47; female, 54).

\section{Radiographic analysis}

Preoperative and 2-year postoperative anteroposterior and lateral radiographs of the lumbar spine and whole-spine acquired with the subjects in an upright standing position were obtained. The radiologic parameters included the following (Fig. 1): (1) segmental lordotic angle (Cobb angle between the upper and lower endplates of each fused segment), (2) disk height (the mean shortest distance between the lower and upper endplates at the anterior and posterior borders), (3) LL (Cobb angle between the upper endplates of both L1 and S1), (4) pelvic tilt (PT; angle between the line joining the midpoint of the upper endplate of S1 with the center of the hip joint and a vertical line), (5) PI (angle between the line linking the midpoint of the upper endplate of S1 with the center of the hip joint and a line vertical to the upper endplate of the sacrum), (6) C7 sagittal vertical axis (SVA; distance between the posterosuperior corner of $\mathrm{S} 1$ and a vertical line from the $\mathrm{C} 7$ body center), (7) TK (Cobb angle between the upper endplate of T1 and the lower endplate of T12), and (8) T1 pelvic angle (angle between the line from the femoral head axis to the centroid of $\mathrm{T} 1$, and the line from the femoral head axis to the middle of the S1 superior endplate) [13]. 


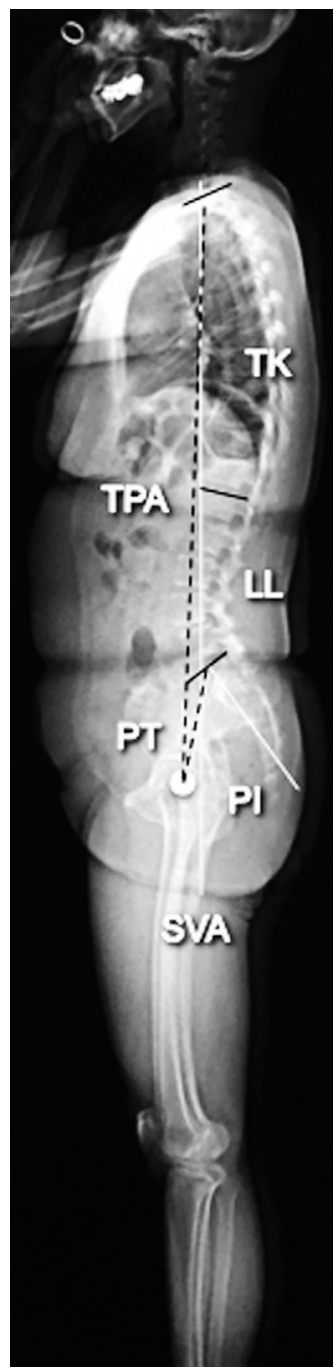

Fig. 1. A scheme of the radiologic parameters investigated. TK, thoracic kyphosis; TPA, T1 pelvic angle; LL, lumbar lordosis; PT, pelvic tilt; $\mathrm{PI}$, pelvic incidence; SVA, C7 sagittal vertical axis.

\section{Surgical procedure for posterior lumbar interbody fu- sion}

The general technique for PLIF has been described previously [14,15]. Briefly, after bilateral pedicle screw insertion, an intervertebral space was created using an intervertebral distractor. Total discectomy was performed after connecting pedicle screws using a rod, and two interbody cages were inserted. The cage height and angle ranged from $7 \mathrm{~mm}$ to $11 \mathrm{~mm}$ and $0^{\circ}$ to $12^{\circ}$, respectively. The bone graft was packed around the cages, and the pedicle screws were disconnected from the rod to relieve the distraction force and, then, reconnected.

\section{Surgical procedure for lateral lumbar interbody fusion}

The general technique for LLIF has been described previously $[9,16]$. Briefly, extremely lateral lumbar fusion using Coroent cages (NuVasive Inc., San Diego, CA, USA) of the $10^{\circ}$ lordotic type was performed in all cases. The cage width, height, and length ranged from 45 to $55 \mathrm{~mm}, 8$ to $12 \mathrm{~mm}$, and 18 to $22 \mathrm{~mm}$, respectively. All the patients underwent bilateral pedicle screw fixation after LLIF, avoiding strong any compression force on the pedicle screws.

\section{Statistical analysis}

IBM SPSS ver. 21.0 (IBM Corp., Armonk, NY, USA) was used for statistical analysis. The values are presented as the mean \pm standard deviation. Student $t$-test and Fisher's exact text were used to compare the two groups. All $p<0.05$ denoted significance.

\section{Results}

Of the 144 patients who underwent PLIF (193 fused levels), 109, 21, and 14 patients underwent 1-, 2-, and 3-level fusions, respectively. In comparison, of 101 patients who underwent LLIF (159 fused levels), 58, 28, and 15 patients underwent 1-, 2-, and 3-level fusions, respectively. Patients' backgrounds and preoperative radiographic parameters for any level of fusion did not differ significantly between PLIF and LLIF procedures (Table 1). The L4L5 level was the most frequently involved level (206/352, $58.5 \%)$, followed by L3-L4 (113/352, 32.1\%) and L2-L3 (33/352, 9.4\%).

The LLIF group exhibited significantly greater changes at 1-level fusion compared to the PLIF group in the parameters of segmental lordotic angle $\left(5.1^{\circ} \pm 5.8^{\circ}\right.$ versus $\left.2.1^{\circ} \pm 5.0^{\circ}, p<0.001\right)$, disk height $(4.2 \pm 2.3 \mathrm{~mm}$ versus $2.2 \pm 2.0 \mathrm{~mm}, p<0.001)$, LL $\left(7.8^{\circ} \pm 7.6^{\circ}\right.$ versus $3.9^{\circ} \pm 8.6^{\circ}$, $p=0.004)$, and PI-LL $\left(-6.9^{\circ} \pm 6.8^{\circ}\right.$ versus $-3.6^{\circ} \pm 10.1^{\circ}$, $p=0.03$ ) (Table 1), but not of others.

Similarly, the LLIF group exhibited significantly greater changes at 2-level fusion compared to the PLIF group in the parameters of segmental lordotic angle $\left(4.8^{\circ} \pm 4.0^{\circ}\right.$ versus $\left.2.6^{\circ} \pm 3.2^{\circ}, p=0.04\right)$, disk height $(4.0 \pm 1.5 \mathrm{~mm}$ versus $2.4 \pm 1.9 \mathrm{~mm}, p=0.002)$, LL $\left(8.4^{\circ} \pm 7.0^{\circ}\right.$ versus $2.1^{\circ} \pm 6.7^{\circ}$, $p=0.003)$, and PI-LL $\left(-9.0^{\circ} \pm 7.3^{\circ}\right.$ versus $-3.4^{\circ} \pm 7.4^{\circ}$, $p=0.001$ ) (Table 2).

In contrast, while changes in the LLIF group did not 
Table 1. Comparisons of patients' backgrounds and radiologic parameters between PLIF and LLIF in cases of 1-level fusion

\begin{tabular}{|c|c|c|c|}
\hline Variable & PLIF & LLIF & $p$-value \\
\hline No. of patients & 109 & 58 & \\
\hline Age (yr) & $66.3 \pm 12.8$ & $69.1 \pm 6.7$ & 0.12 \\
\hline Gender (male:female) & $51: 58$ & $29: 29$ & 0.75 \\
\hline Body mass index $\left(\mathrm{kg} / \mathrm{m}^{2}\right)$ & $24.5 \pm 3.8$ & $23.9 \pm 3.2$ & 0.27 \\
\hline Preop JOA score & $13.0 \pm 4.8$ & $14.5 \pm 4.4$ & 0.06 \\
\hline Levels of surgery & & & 0.46 \\
\hline $\mathrm{L} 2 / 3$ & 1 & 2 & \\
\hline $\mathrm{L} 3 / 4$ & 22 & 13 & \\
\hline$\llcorner 4 / 5$ & 86 & 43 & \\
\hline \multicolumn{4}{|l|}{ Interbody cage } \\
\hline Height (mm) & $9.6 \pm 1.0$ & $9.3 \pm 0.9$ & 0.60 \\
\hline Angle $\left({ }^{\circ}\right)$ & $1.3 \pm 2.4$ & $10.0 \pm 0.0$ & $<0.001^{\text {a) }}$ \\
\hline \multicolumn{4}{|c|}{ Preop radiologic measurement } \\
\hline $\operatorname{SLA}\left({ }^{\circ}\right)$ & $8.0 \pm 11.0$ & $6.8 \pm 8.6$ & 0.47 \\
\hline $\mathrm{DH}(\mathrm{mm})$ & $6.5 \pm 7.9$ & $7.5 \pm 2.7$ & 0.36 \\
\hline $\mathrm{PI}\left({ }^{\circ}\right)$ & $51.9 \pm 10.8$ & $50.3 \pm 10.7$ & 0.36 \\
\hline $\mathrm{LL}\left({ }^{\circ}\right)$ & $33.9 \pm 15.5$ & $36.5 \pm 15.3$ & 0.30 \\
\hline $\mathrm{PI}-\mathrm{LL}\left({ }^{\circ}\right)$ & $18.1 \pm 16.3$ & $13.8 \pm 13.6$ & 0.09 \\
\hline $\operatorname{PT}\left({ }^{\circ}\right)$ & $22.1 \pm 8.7$ & $21.2 \pm 9.0$ & 0.53 \\
\hline $\operatorname{SS}\left(1^{\circ}\right)$ & $29.3 \pm 8.7$ & $29.7 \pm 10.0$ & 0.79 \\
\hline SVA (mm) & $42.8 \pm 34.7$ & $52.1 \pm 38.9$ & 0.12 \\
\hline $\operatorname{TK}\left(l^{\circ}\right)$ & $32.8 \pm 12.6$ & $35.4 \pm 12.3$ & 0.20 \\
\hline $\operatorname{TPA}\left({ }^{\circ}\right)$ & $19.0 \pm 9.9$ & $22.1 \pm 13.8$ & 0.10 \\
\hline \multicolumn{4}{|c|}{ Changes in radiologic parameters (postop-preop) } \\
\hline$\triangle S L A\left(^{\circ}\right)$ & $2.1 \pm 5.0$ & $5.1 \pm 5.8$ & $<0.001^{\text {a) }}$ \\
\hline$\Delta \mathrm{DH}(\mathrm{mm})$ & $2.2 \pm 2.0$ & $4.2 \pm 2.3$ & $<0.001^{\text {a) }}$ \\
\hline$\Delta \mathrm{LL}\left({ }^{\circ}\right)$ & $3.9 \pm 8.6$ & $7.8 \pm 7.6$ & $0.004^{\mathrm{al}}$ \\
\hline$\Delta \mathrm{PI}-\mathrm{LL}\left({ }^{\circ}\right)$ & $-3.6 \pm 10.1$ & $-6.9 \pm 6.8$ & $0.03^{\mathrm{a})}$ \\
\hline$\Delta \mathrm{PT}\left({ }^{\circ}\right)$ & $-1.3 \pm 6.8$ & $-2.6 \pm 5.6$ & 0.22 \\
\hline$\triangle S V A(m m)$ & $-11.8 \pm 33.5$ & $-17.5 \pm 37.2$ & 0.32 \\
\hline$\triangle T K\left({ }^{\circ}\right)$ & $0.4 \pm 10.5$ & $1.6 \pm 7.2$ & 0.44 \\
\hline$\triangle T P A\left({ }^{\circ}\right)$ & $-0.9 \pm 12.7$ & $-3.8 \pm 10.5$ & 0.14 \\
\hline
\end{tabular}

Values are presented as number or mean \pm standard deviation.

PLIF, posterior lumbar interbody fusion; LLIF, lateral lumbar interbody fusion; preop, preoperative; postop, postoperative; JOA, Japanese Orthopedic Association; SLA, segmental lordotic angle; DH, disc height; LL, lumbar lordosis; PI, pelvic incidence; PT, pelvic tilt; SVA, C7 sagittal vertical axis; TK, thoracic kyphosis; TPA, T1 pelvic angle.

${ }^{\text {a) }}$ Statistically significant.

differ significantly from that in the PLIF group at 3-level fusion in the parameters of segmental lordotic angle $\left(4.8^{\circ} \pm 3.3^{\circ}\right.$ versus $\left.2.6^{\circ} \pm 3.2^{\circ}, p=0.08\right)$ and disk height $(4.1 \pm 2.1 \mathrm{~mm}$ versus $2.9 \pm 1.1 \mathrm{~mm}, p=0.07)$ (Table 3$)$, significantly greater changes were observed in LL $\left(12.1^{\circ} \pm 11.1^{\circ}\right.$ versus $\left.4.2^{\circ} \pm 9.1^{\circ}, p=0.047\right)$ and PI-LL $\left(-11.2^{\circ} \pm 11.3^{\circ}\right.$ versus $-3.0^{\circ} \pm 9.3^{\circ}, p=0.043$ ) (Figs. 2, 3). Additionally, significantly greater changes were observed in the LLIF group regarding PT $\left(-6.4^{\circ} \pm 4.9^{\circ}\right.$ versus $\left.-2.5^{\circ} \pm 5.3^{\circ}, p=0.049\right)$ and TK $\left(7.8^{\circ} \pm 11.8^{\circ}\right.$ versus $\left.-0.3^{\circ} \pm 9.7^{\circ}, p=0.047\right)$ (Table 3 ). 
Table 2. Comparisons of patients' backgrounds and radiologic parameters between PLIF and LLIF in cases of 2-level fusion

\begin{tabular}{|c|c|c|c|}
\hline Variable & PLIF & LLIF & $p$-value \\
\hline No. of patients & 21 & 28 & \\
\hline Age (yr) & $69.4 \pm 9.3$ & $73.1 \pm 4.2$ & 0.07 \\
\hline Gender (male:female) & $10: 21$ & 10:18 & 0.79 \\
\hline Body mass index $\left(\mathrm{kg} / \mathrm{m}^{2}\right)$ & $23.4 \pm 3.5$ & $25.2 \pm 2.9$ & 0.06 \\
\hline Preop JOA score & $11.3 \pm 2.9$ & $13.1 \pm 4.6$ & 0.13 \\
\hline Levels of surgery & & & 0.77 \\
\hline $\mathrm{L} 2 / 3$ & 0 & 1 & \\
\hline $\mathrm{L} 3 / 4$ & 21 & 28 & \\
\hline$L 4 / 5$ & 21 & 27 & \\
\hline \multicolumn{4}{|l|}{ Interbody cage } \\
\hline Height (mm) & $9.6 \pm 1.0$ & $9.5 \pm 1.0$ & 0.73 \\
\hline Angle $\left({ }^{\circ}\right)$ & $1.3 \pm 2.0$ & $10.0 \pm 0.0$ & $<0.001^{a \mid}$ \\
\hline \multicolumn{4}{|c|}{ Preop radiologic measurement } \\
\hline $\operatorname{SLA}\left({ }^{\circ}\right)$ & $5.2 \pm 5.4$ & $5.3 \pm 5.0$ & 0.95 \\
\hline $\mathrm{DH}(\mathrm{mm})$ & $6.8 \pm 2.1$ & $6.1 \pm 2.6$ & 0.32 \\
\hline $\operatorname{PI}\left({ }^{\circ}\right)$ & $53.0 \pm 10.0$ & $49.4 \pm 6.9$ & 0.14 \\
\hline $\mathrm{LL}\left({ }^{\circ}\right)$ & $32.7 \pm 11.9$ & $31.6 \pm 13.4$ & 0.77 \\
\hline $\mathrm{PI}-\mathrm{LL}\left({ }^{\circ}\right)$ & $15.3 \pm 12.4$ & $17.8 \pm 14.2$ & 0.52 \\
\hline $\operatorname{PT}\left({ }^{\circ}\right)$ & $21.4 \pm 8.9$ & $21.6 \pm 6.6$ & 0.93 \\
\hline SVA (mm) & $56.3 \pm 27.7$ & $65.9 \pm 45.5$ & 0.40 \\
\hline $\operatorname{TK}\left({ }^{\circ}\right)$ & $30.2 \pm 14.1$ & $32.9 \pm 8.6$ & 0.41 \\
\hline $\operatorname{TPA}\left({ }^{\circ}\right)$ & $24.1 \pm 10.9$ & $24.0 \pm 8.4$ & 0.97 \\
\hline \multicolumn{4}{|c|}{ Changes in radiologic parameters (post-preop) } \\
\hline$\triangle \operatorname{SLA}\left({ }^{\circ}\right)$ & $2.6 \pm 3.2$ & $4.8 \pm 4.0$ & $0.04^{\mathrm{al}}$ \\
\hline$\Delta \mathrm{DH}(\mathrm{mm})$ & $2.4 \pm 1.9$ & $4.0 \pm 1.5$ & $0.002^{a)}$ \\
\hline$\Delta \mathrm{LL}\left({ }^{\circ}\right)$ & $2.1 \pm 6.7$ & $8.4 \pm 7.0$ & $0.003^{\mathrm{a}}$ \\
\hline$\Delta \mathrm{PI}-\mathrm{LL}\left({ }^{\circ}\right)$ & $-3.4 \pm 7.4$ & $-9.0 \pm 7.3$ & $0.001^{\mathrm{a}}$ \\
\hline$\triangle P T\left({ }^{\circ}\right)$ & $-2.6 \pm 6.1$ & $-3.0 \pm 5.1$ & 0.80 \\
\hline$\triangle S V A(m m)$ & $-12.1 \pm 30.3$ & $-19.1 \pm 31.3$ & 0.44 \\
\hline$\triangle T K\left({ }^{\circ}\right)$ & $3.0 \pm 10.1$ & $1.8 \pm 7.4$ & 0.63 \\
\hline$\triangle \mathrm{TPA}\left({ }^{\circ}\right)$ & $-0.5 \pm 9.7$ & $-3.8 \pm 6.1$ & 0.15 \\
\hline
\end{tabular}

Values are presented as number or mean \pm standard deviation.

PLIF, posterior lumbar interbody fusion; LLIF, lateral lumbar interbody fusion; preop, preoperative; postop, postoperative; JOA, Japanese Orthopedic Association; SLA, segmental lordotic angle; DH, disc height; LL, lumbar lordosis; PI, pelvic incidence; PT, pelvic tilt; SVA, C7 sagittal vertical axis; TK, thoracic kyphosis; TPA, T1 pelvic angle.

a) Statistically significant.

\section{Discussion}

To our knowledge, this is the first study that compared sagittal realignment after PLIF and LLIF in short-level spinal fusion surgeries. Compared to conventional PLIF, we found that LLIF can provide better local lordotic angle, disk height, and LL after 1- and 2-level fusion. Furthermore, the degree of correction of spinopelvic alignment as assessed using PT, as well as TK were significantly greater with 3-level fusion using LLIF. Overall, LLIF has a greater potential than PLIF to correct sagittal alignment even after short-level lumbar interbody fusion. 
Table 3. Comparisons of patients' backgrounds and radiologic parameters between PLIF and LLIF in cases of 3-level fusion

\begin{tabular}{|c|c|c|c|}
\hline Variable & PLIF & LLIF & $p$-value \\
\hline No. of patients & 14 & 15 & \\
\hline Age (yr) & $66.4 \pm 13.4$ & $72.8 \pm 5.8$ & 0.10 \\
\hline Gender (male:female) & $7: 7$ & $8: 7$ & 1.00 \\
\hline Body mass index $\left(\mathrm{kg} / \mathrm{m}^{2}\right)$ & $25.2 \pm 5.1$ & $25.1 \pm 4.2$ & 0.93 \\
\hline Preop JOA score & $11.8 \pm 5.6$ & $13.0 \pm 2.5$ & 0.48 \\
\hline Levels of surgery & & & 1.00 \\
\hline $\mathrm{L} 2 / 3$ & 14 & 15 & \\
\hline $\mathrm{L} 3 / 4$ & 14 & 15 & \\
\hline$\llcorner 4 / 5$ & 14 & 15 & \\
\hline \multicolumn{4}{|l|}{ Interbody cage } \\
\hline Height (mm) & $9.1 \pm 0.9$ & $9.1 \pm 0.8$ & 1.00 \\
\hline Angle $\left({ }^{\circ}\right)$ & $1.3 \pm 2.2$ & $10.0 \pm 0.0$ & $<0.001^{\text {a) }}$ \\
\hline \multicolumn{4}{|c|}{ Preop radiologic measurement } \\
\hline $\operatorname{SLA}\left({ }^{\circ}\right)$ & $5.3 \pm 7.9$ & $4.5 \pm 3.6$ & 0.72 \\
\hline $\mathrm{DH}(\mathrm{mm})$ & $6.5 \pm 2.4$ & $5.8 \pm 2.2$ & 0.42 \\
\hline $\operatorname{PI}\left({ }^{\circ}\right)$ & $51.3 \pm 11.5$ & $47.5 \pm 8.5$ & 0.32 \\
\hline $\mathrm{LL}\left({ }^{\circ}\right)$ & $34.7 \pm 15.1$ & $23.9 \pm 18.9$ & 0.10 \\
\hline $\mathrm{PI}-\mathrm{LL}\left({ }^{\circ}\right)$ & $16.9 \pm 15.6$ & $19.6 \pm 17.5$ & 0.67 \\
\hline $\operatorname{PT}\left({ }^{\circ}\right)$ & $21.8 \pm 8.9$ & $26.6 \pm 9.0$ & 0.16 \\
\hline SVA (mm) & $45.6 \pm 35.1$ & $66.4 \pm 43.9$ & 0.17 \\
\hline $\operatorname{TK}\left({ }^{\circ}\right)$ & $31.3 \pm 12.9$ & $29.2 \pm 10.7$ & 0.63 \\
\hline $\operatorname{TPA}\left({ }^{\circ}\right)$ & $20.4 \pm 10.8$ & $27.6 \pm 10.6$ & 0.08 \\
\hline \multicolumn{4}{|c|}{ Changes in radiologic parameters (postop-preop) } \\
\hline$\triangle S L A\left({ }^{\circ}\right)$ & $2.6 \pm 3.2$ & $4.8 \pm 3.3$ & 0.08 \\
\hline$\Delta \mathrm{DH}(\mathrm{mm})$ & $2.9 \pm 1.1$ & $4.1 \pm 2.1$ & 0.07 \\
\hline$\Delta \mathrm{LL}\left({ }^{\circ}\right)$ & $4.2 \pm 9.1$ & $12.1 \pm 11.1$ & $0.047^{a)}$ \\
\hline$\Delta \mathrm{Pl}-\mathrm{LL}\left({ }^{\circ}\right)$ & $-3.0 \pm 9.3$ & $-11.2 \pm 11.3$ & $0.043^{\text {a) }}$ \\
\hline$\Delta \mathrm{PT}\left({ }^{\circ}\right)$ & $-2.5 \pm 5.3$ & $-6.4 \pm 4.9$ & $0.049^{a)}$ \\
\hline$\triangle S V A(m m)$ & $-15.5 \pm 45.7$ & $-18.4 \pm 26.8$ & 0.84 \\
\hline$\triangle \operatorname{TK}\left({ }^{\circ}\right)$ & $-0.3 \pm 9.7$ & $7.8 \pm 11.8$ & $0.047^{a)}$ \\
\hline$\triangle \operatorname{TPA}\left({ }^{\circ}\right)$ & $-2.8 \pm 9.4$ & $-5.8 \pm 7.6$ & 0.35 \\
\hline
\end{tabular}

Values are presented as number or mean \pm standard deviation.

PLIF, posterior lumbar interbody fusion; LLIF, lateral lumbar interbody fusion; preop, preoperative; postop, postoperative; JOA, Japanese Orthopedic Association; SLA, segmental lordotic angle; DH, disc height; PI, pelvic incidence; LL, lumbar lordosis; PT, pelvic tilt; SVA, C7 sagittal vertical axis; TK, thoracic kyphosis; TPA, T1 pelvic angle.

a) Statistically significant.

LLIF was introduced as a treatment for axial low back pain by Ozgur et al. [9], and subsequently used by Oliveira et al. [10], for treating central canal or foraminal stenosis. Compared with conventional open procedures, minimally invasive lumbar interbody fusion using LLIF is more effective at achieving spinal fusion with lower morbidity [10]. Other advantages of the LLIF procedure include gaining better access to the disk space than posterior approaches which permits maximal disk excision, endplate preparation, and use of larger bone grafts [9]. Furthermore, the interbody cage used in LLIF provides an extension-distraction moment to the anterior and middle 

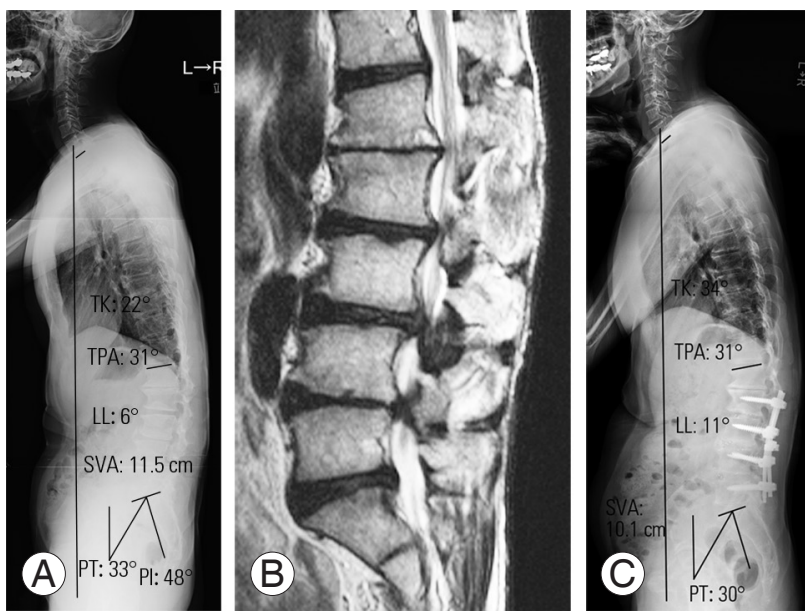

Fig. 2. A 61-year-old male patient with low back pain and intermittent claudication. (A) A preoperative whole-spine standing lateral radiograph showed the following findings: $\mathrm{LL}=6^{\circ}, \mathrm{PT}=33^{\circ}, \mathrm{Pl}=48^{\circ}$, SVA $=11.5$ $\mathrm{cm}, \mathrm{TK}=22^{\circ}$, and $\mathrm{TPA}=37^{\circ}$. (B) Severe stenosis was observed from $\mathrm{L} 2-3$ to $\mathrm{L} 4-5$ on T2 sagittal images obtained using magnetic resonance imaging. (C) A whole-spine standing radiograph at 2 years following posterior lumbar interbody fusion from $L 2-3$ to $L 4-5$. The radiograph revealed improvements of $11^{\circ}, 30^{\circ}$, and $10.1 \mathrm{~cm}$ in $\mathrm{LL}, \mathrm{PT}$, and SVA, respectively. TK, thoracic kyphosis; TPA, T1 pelvic angle; LL, lumbar lordosis; SVA, C7 sagittal vertical axis; PT, pelvic tilt; PI, pelvic incidence.
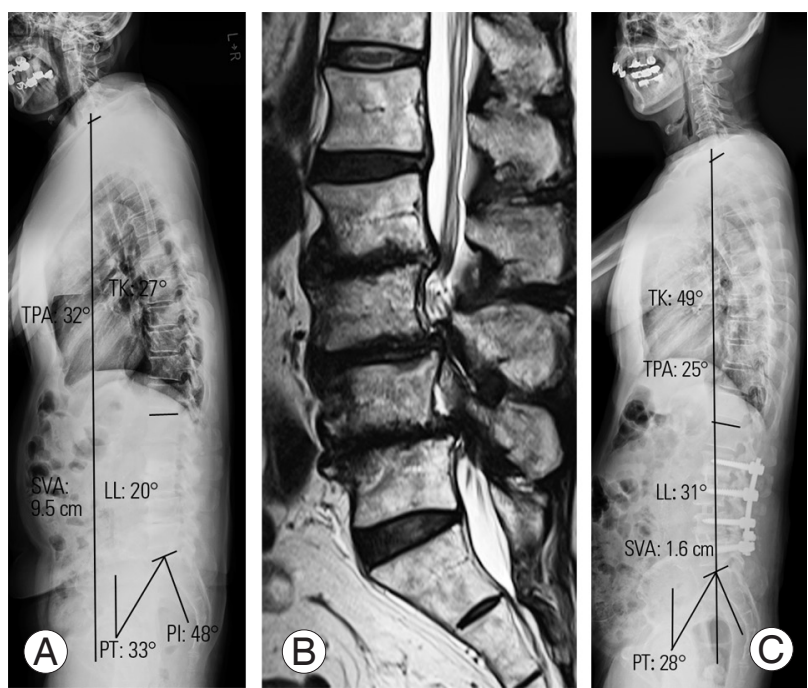

Fig. 3. A 68-year-old male patient with low back pain, bilateral leg pain, and intermittent claudication. (A) A preoperative whole-spine standing lateral radiograph revealed the following findings: $L L=20^{\circ}$, $\mathrm{PT}=33^{\circ}, \mathrm{Pl}=48^{\circ}, \mathrm{SVA}=9.5 \mathrm{~cm}, \mathrm{TK}=27^{\circ}$, and TPA $=32^{\circ}$. (B) Severe stenosis was observed from $L 2-3$ to $L 4-5$ on $T 2$ sagittal images obtained using magnetic resonance imaging. (C) A whole-spine standing radiograph at 2 years following lateral lumbar interbody fusion from $\mathrm{L} 2-3$ to L4-5. The radiograph illustrated improvements of $31^{\circ}, 28^{\circ}$, and $1.6 \mathrm{~cm}$ in LL, PT, and SVA, respectively. TK, thoracic kyphosis; TPA, T1 pelvic angle; SVA, C7 sagittal vertical axis; LL, lumbar lordosis; PT, pelvic tilt; $\mathrm{PI}$, pelvic incidence. columns of the lumbar spine, effectively permitting the enlargement of the interbody space and neuroforaminal height $[11,17]$. When combined with posterior fixation, LLIF facilitates sufficient correction of both coronal and sagittal deformities in patients with degenerative scoliosis, with smaller blood loss and lower morbidity than PLIF $[17,18]$. However, regarding the effects on global alignment in short-level spinal fusion surgeries, in contrast to PLIF, LLIF is less well understood. Furthermore, the lack of comparative studies between LLIF and PLIF on radiographic outcomes in the context of sagittal balance in patients with degenerative lumbar diseases requiring short-level spinal fusion surgeries warranted the current investigation.

Increase in disc height and segmental lordosis with LLIF is not without precedence [19]. Local sagittal alignment changes after LLIF were demonstrated by Oliveira et al. [10], who reported increases of $41.9 \%$ and $13.5 \%$, and Alimi et al. [20] who showed increases of $83 \%$ and $26 \%$ in the intervertebral disc and foraminal height, respectively. Anand et al. [21], evaluated acquired segmental lordosis after LLIF, and reported that using a $10^{\circ}$ cage can provide an $8.1^{\circ}$ increase in segmental lordosis in adults with spinal deformity. A similar $10^{\circ}$ lordotic cage in the current study provided a $5^{\circ}$ increase without posterior column osteotomy in patients with degenerative lumbar diseases requiring short-level spinal fusion surgeries. Therefore, it can be postulated that the background of the patient determines the acquired segmental lordotic angle, which may be greater in patients with deformity and preoperative sagittal imbalance [8]. Correspondingly, the smaller the lordotic cage angle, the smaller is the acquired segmental lordotic angle. Acosta et al. [22] investigated changes in spinal alignment following LLIF with $6^{\circ}$ lordotic cages (mean fusion level, 1.8 levels) in 36 patients; they reported that the mean segmental lordosis had increased (5.3 preoperatively versus 8.2 postoperatively, $p<0.0001)$. Additionally, Shiga et al. [23] investigated segmental lordosis after LLIF using $6^{\circ}$ lordotic cages in 80 patients (mean fusion level, 1.5 levels), reporting that the average correction angle was $3.8^{\circ}$. Thus, angles of the inserted cages affect the local radiographic outcome.

Although an increase in segmental lordosis has been reported following PLIF, the magnitude of change was smaller than that after LLIF. Cho et al. [8] reported changes in the segmental angle of $0.1^{\circ}-4.7^{\circ}$ in patients with and without sagittal imbalance after 1- or 2-level PLIF using a 
$4^{\circ}$ lordotic cage. While changes in segmental lordosis were not observed with PLIF using $0^{\circ}$ cages, modest increase of $0.1^{\circ}$ [24], or even a decrease in segmental lordosis from $14.0^{\circ}$ to $12.8^{\circ}$ [25], after PLIF have been noted. In the conventional PLIF approach, the difficulty associated with inserting hyperlordotic cages to create adequate segmental lordosis, justifies the need for invasive spinal osteotomy $[25,26]$.

We found significant changes in LL; however, global sagittal alignment did not change dramatically after shortlevel spinal fusion surgeries, indicating a lack of consensus regarding postoperative changes after short-level lumbar interbody fusion. In general, acquired LL could be affected by segmental lordosis at the surgically targeted levels easily; however, there are several compensatory mechanisms in global sagittal alignment. Cho et al. [8] noticed improvement in global sagittal balance after 1- or 2-level PLIF only in patients with preoperative sagittal imbalance. The lack of a significant change in global sagittal alignment, including SVA after either PLIF or LLIF in the present study could be attributed to the fact that most patients did not exhibit preoperative sagittal imbalance.

A few limitations of the current study should be acknowledged. First, as this was a retrospective analysis, the angles of the utilized cages inevitably varied among patients who underwent PLIF. The results cannot necessarily be interpreted as derived from a specific cage design, and may be attributed to the 'conventional standard' PLIF although these variations could affect postoperative sagittal alignment. Second, the exclusion of a number of patients who underwent 2- or 3-level fusion affected the statistical power of these cases and calculation of sample size is warranted for future prospective studies to validate our results. Last, despite attempting to insert LLIF cages into the anterior one-third of the disc space, the exact location of interbody cages as demonstrated previously [23], was not investigated in this study. As the results of local lordosis and LL may differ depending on cage locations, this may be a limitation of the current study.

\section{Conclusions}

LLIF provided better segmental lordosis and LL than conventional standard PLIF in cases of short-level spinal fusion surgeries. In patients undergoing multilevel interbody fusion surgery, PT and TK were significantly altered after LLIF, and spinopelvic harmony was enhanced, even after short-level LLIF. Thus, LLIF was demonstrated to be a useful lumbar interbody fusion technique, constituting a powerful tool for achieving sagittal realignment with minimal surgical invasiveness.

\section{Conflict of Interest}

No potential conflict of interest relevant to this article was reported.

\section{References}

1. Glassman SD, Bridwell K, Dimar JR, Horton W, Berven S, Schwab F. The impact of positive sagittal balance in adult spinal deformity. Spine (Phila Pa 1976) 2005;30:2024-9.

2. Schwab F, Patel A, Ungar B, Farcy JP, Lafage V. Adult spinal deformity-postoperative standing imbalance: how much can you tolerate?: an overview of key parameters in assessing alignment and planning corrective surgery. Spine (Phila Pa 1976) 2010;35:2224-31.

3. Schwab FJ, Blondel B, Bess S, et al. Radiographical spinopelvic parameters and disability in the setting of adult spinal deformity: a prospective multicenter analysis. Spine (Phila Pa 1976) 2013;38:E803-12.

4. Jang JS, Lee SH, Min JH, Maeng DH. Influence of lumbar lordosis restoration on thoracic curve and sagittal position in lumbar degenerative kyphosis patients. Spine (Phila Pa 1976) 2009;34:280-4.

5. Rothenfluh DA, Mueller DA, Rothenfluh E, Min K. Pelvic incidence-lumbar lordosis mismatch predisposes to adjacent segment disease after lumbar spinal fusion. Eur Spine J 2015;24:1251-8.

6. Umehara S, Zindrick MR, Patwardhan AG, et al. The biomechanical effect of postoperative hypolordosis in instrumented lumbar fusion on instrumented and adjacent spinal segments. Spine (Phila Pa 1976) 2000;25:1617-24.

7. Kadam A, Wigner N, Saville P, Arlet V. Overpowering posterior lumbar instrumentation and fusion with hyperlordotic anterior lumbar interbody cages followed by posterior revision: a preliminary feasibility study. J Neurosurg Spine 2017;27:650-60.

8. Cho JH, Joo YS, Lim C, Hwang CJ, Lee DH, Lee CS. Effect of one- or two-level posterior lumbar interbody fusion on global sagittal balance. Spine J 


\section{7;17:1794-802.}

9. Ozgur BM, Aryan HE, Pimenta L, Taylor WR. Extreme lateral interbody fusion (XLIF): a novel surgical technique for anterior lumbar interbody fusion. Spine J 2006;6:435-43.

10. Oliveira L, Marchi L, Coutinho E, Pimenta L. A radiographic assessment of the ability of the extreme lateral interbody fusion procedure to indirectly decompress the neural elements. Spine (Phila Pa 1976) 2010;35:S331-7.

11. Pimenta L, Turner AW, Dooley ZA, Parikh RD, Peterson $\mathrm{MD}$. Biomechanics of lateral interbody spacers: going wider for going stiffer. ScientificWorldJournal 2012;2012:381814.

12. Schwab F, Blondel B, Chay E, et al. The comprehensive anatomical spinal osteotomy classification. Neurosurgery 2014;74:112-20.

13. Protopsaltis T, Schwab F, Bronsard N, et al. The T1 pelvic angle, a novel radiographic measure of global sagittal deformity, accounts for both spinal inclination and pelvic tilt and correlates with health-related quality of life. J Bone Joint Surg Am 2014;96:1631-40.

14. Kanemura T, Ishikawa $\mathrm{Y}$, Matsumoto A, et al. The maturation of grafted bone after posterior lumbar interbody fusion with an interbody carbon cage: a prospective five-year study. J Bone Joint Surg Br 2011;93:1638-45.

15. Kanemura T, Matsumoto A, Ishikawa Y, et al. Radiographic changes in patients with pseudarthrosis after posterior lumbar interbody arthrodesis using carbon interbody cages: a prospective five-year study. J Bone Joint Surg Am 2014;96:e82.

16. Satake K, Kanemura T, Yamaguchi H, Segi N, Ouchida J. Predisposing factors for intraoperative endplate injury of extreme lateral interbody fusion. Asian Spine J 2016;10:907-14.

17. Tempel ZJ, Gandhoke GS, Bonfield CM, Okonkwo DO, Kanter AS. Radiographic and clinical outcomes following combined lateral lumbar interbody fusion and posterior segmental stabilization in patients with adult degenerative scoliosis. Neurosurg Focus 2014;36:E11.

18. Caputo AM, Michael KW, Chapman TM, et al. Extreme lateral interbody fusion for the treatment of adult degenerative scoliosis. J Clin Neurosci 2013;20:1558-63.

19. Costanzo G, Zoccali C, Maykowski P, Walter CM, Skoch J, Baaj AA. The role of minimally invasive lateral lumbar interbody fusion in sagittal balance correction and spinal deformity. Eur Spine J 2014;23:699-704.

20. Alimi M, Hofstetter CP, Cong GT, et al. Radiological and clinical outcomes following extreme lateral interbody fusion. J Neurosurg Spine 2014;20:623-35.

21. Anand N, Cohen RB, Cohen J, Kahndehroo B, Kahwaty S, Baron E. The influence of lordotic cages on creating sagittal balance in the CMIS treatment of adult spinal deformity. Int J Spine Surg 2017;11:23.

22. Acosta FL, Liu J, Slimack N, Moller D, Fessler R, Koski T. Changes in coronal and sagittal plane alignment following minimally invasive direct lateral interbody fusion for the treatment of degenerative lumbar disease in adults: a radiographic study. J Neurosurg Spine 2011;15:92-6.

23. Shiga $\mathrm{Y}$, Orita $\mathrm{S}$, Inage $\mathrm{K}$, et al. Evaluation of the location of intervertebral cages during oblique lateral interbody fusion surgery to achieve sagittal correction. Spine Surg Relat Res 2017;1:197-202.

24. Rice JW, Sedney CL, Daffner SD, Arner JW, Emery SE, France JC. Improvement of segmental lordosis in transforaminal lumbar interbody fusion: a comparison of two techniques. Global Spine J 2016;6:229-33.

25. Matsumoto T, Okuda S, Maeno T, et al. Spinopelvic sagittal imbalance as a risk factor for adjacent-segment disease after single-segment posterior lumbar interbody fusion. J Neurosurg Spine 2017;26:435-40.

26. Yson SC, Santos ER, Sembrano JN, Polly DW Jr. Segmental lumbar sagittal correction after bilateral transforaminal lumbar interbody fusion. J Neurosurg Spine 2012;17:37-42. 